\title{
Dampak Kebijakan Jaminan Kesehatan Nasional terhadap Efisiensi Rumah Sakit: Studi Kasus di Provinsi Sulawesi Selatan
}

\section{The Effect of Health Insurance National Reform on Hospital Efficiency in Indonesia: The Case Study of South Sulawesi Province}

\author{
Irwandy ${ }^{1,2^{*}}$, Amal C. Sjaaf ${ }^{3}$ \\ ${ }^{1}$ Mahasiswa Program Doktoral, Fakultas Kesehatan Masyarakat, Universitas Indonesia. \\ ${ }^{2}$ Bagian Manajemen Rumah Sakit, Fakultas Kesehatan Masyarakat, Universitas Hasanuddin. \\ ${ }^{3}$ Departemen Administrasi dan Kebijakan Kesehatan, Fakultas Kesehatan Masyarakat, Universitas Indonesia \\ (*wandy_email@yahoo.co.id)
}

\begin{abstract}
ABSTRAK
Memasuki Era Jaminan Kesehatan Nasional (JKN), pengelolaan rumah sakit yang efisien dengan tetap memperhatikan kendali mutu dan biaya menjadi kunci agar mampu bertahan dan berkembang. Tujuan penelitian adalah untuk mengetahui dampak penerapan kebijakan JKN terhadap tingkat efisiensi rumah sakit di Provinsi Sulawesi Selatan. Efisiensi RS dinilai dengan metode Data Envelopment Analisis (DEA). Sampel adalah seluruh rumah sakit umum yang telah berstatus badan layanan umum daerah di Provinsi Sulawesi Selatan. Jumlah sampel penelitian sebanyak 25 rumah sakit. Data yang dianalisis adalah data tahun 2014 hingga 2017. Hasil penelitian menunjukkan rata-rata RS BLUD di Provinsi Sulawesi Selatan hanya efisien pada tahun 2016 sedangkan pada tahun 2014, 2015 dan 2017 rata-rata RS tidak efisien. Perubahan sistem pelayanan kesehatan pada era JKN telah membawa dampak negatif terhadap tingkat efisiensi RS. Hal ini disebabkan seringnya terjadi keterlambatan pencairan pembayaran klaim BPJS Kesehatan dan rendahnya tarif INA-CBGs. Oleh karena itu pemerintah perlu mengeluarkan kebijakan untuk mengatasi permasalahan tersebut.
\end{abstract}

Kata kunci: Efisiensi, rumah sakit, DEA, JKN

\section{ABSTRACT}

Managing the hospital efficiency with still control the hospital quality and cost is a key to survive in National Health Insurance Era. The objective of this study was to determine the impact of the implementation of the National Health Insurance Policy (NHI) on the efficiency level of Hospital in South Sulawesi Province, Indonesia. The level of efficiency was analyzed using the Data Envelopment Analysis method. The study population was all BLUD hospitals in South Sulawesi Province. The Samples of research were 25 hospitals. Data from years 2014 to 2017 are used to analyze. The results showed, in average the hospitals achive the efficiency level only in year 2016. In years 2014, 2015 and 2017 the hospitals were not efficient. The changing in the healthcare system, especially on payment system to hospitals in JKN era, have had a negative impact on the level of hospital efficiency because the unadequate INA CBGs Tariff and hospital claims payment disrupted. Therefore, the government needs to overcome those problems.

Keywords: Efficiency, hospital, DEA, NHI 


\section{PENDAHULUAN}

Pemerintah Indonesia mulai mengimplementasikan program Jaminan Kesehatan Nasional (JKN) secara universal di Indonesia, sejak tanggal 1 Januari 2014. Program ini bertujuan memberikan jaminan kepada seluruh warga negara Indonesia agar dapat mengakses pelayanan kesehatan ketika membutuhkan dan tidak lagi terkendala khususnya dari segi pembiayaan. Di Indonesia, JKN diimplementasikan secara bertahap oleh pemerintah, diharapkan pada tahun 2019 seluruh warga negara Indonesia telah ikut seluruhnya bergabung ke dalam program ini. JKN di Indonesia menganut sistem asuransi sosial, yakni pemerintah Indonesia mewajibkan seluruh warga negara untuk bergabung pada program ini.

Penerapan JKN saat ini telah membawa perubahan besar dalam sistem pelayanan dan pembiayaan kesehatan khususya di rumah sakit. Sistem pembayaran di rumah sakit berubah yang sebelumnya menggunakan sistem fee for service menjadi sistem pembayaran prospective payment system dengan menggunakan tarif Ina-CBGs dan BPJS Kesehatan ditunjuk sebagai institusi pelaksana program. Sistem rujukan pasien secara berjenjang juga mulai diperlakukan secara lebih ketat dari pelayanan kesehatan primer ke pelayanan kesehatan rujukan atau rumah sakit.

Perubahan kondisi tersebut membuat pihak manajemen rumah sakit harus dapat mengelola rumah sakit mereka secara efisien dengan tetap memperhatikan kendali mutu dan kendali biaya agar mampu bertahan di era Jaminan Kesehatan Nasional. Menyadari akan pentingnya efisiensi, pemerintah Indonesia memperkenalkan Pola Badan Layanan Umum (PK-BLU) sejak tahun 2004 bagi instansi yang menyediakan layanan kepada masyarakat yang diatur dalam Undang-Undang Nomor 1 tahun 2004 tentang Perbendaharaan Negara, termasuk didalamnya adalah Rumah Sakit. Pemerintah Indonesia dalam Undang-Undang Nomor 44 Tahun 2009 tentang Rumah Sakit juga telah mewajibkan bahwa seluruh rumah sakit yang didirikan pemerintah harus dikelola dalam bentuk Badan Layanan Umum (BLU) untuk pemerintah pusat atau Badan Layanan Umum Daerah (BLUD) untuk pemerintah daerah.

Tujuan dari pembentukan Badan Layanan Umum adalah meningkatkan pelayanan kepada masyarakat, rumah sakit diberikan fleksibilitas dalam pengelolaan keuangan berdasarkan prinsip efisiensi, efektifitas dan produktivitas serta penerapan praktik bisnis yang sehat. Dengan adanya fleksibilitas tersebut diharapkan dapat meningkatkan kinerja pelayanan dan kinerja keuangan rumah sakit sehingga mampu memberikan pelayanan kesehatan yang optimal dan dapat berkembang di Era JKN saat ini.

Jumlah RS di Indonesia yang bersatatus BLU/BLUD saat ini terus mengalami peningkatan, salah satu provinsi yang mengalami peningkatan yang cukup signifikan adalah Provinsi Sulawesi Selatan. Tercatat pada tahun 2010 pada 24 kabupaten/kota yang ada di Provinsi Sulawesi Selatan hanya terdapat $10 \mathrm{RS}$ yang telah berstatus BLU/BLUD, tetapi hingga tahun 2016 meningkat menjadi 25 RS atau meningkat sebanyak $150 \%{ }^{1}$ Peningkatan jumlah RS BLU/BLUD saat ini diharapkan dapat diikuti dengan peningkatan mutu kualitas layanan rumah sakit, hal tersebut sesuai dengan tujuan dari penerapan kelembagaan BLU/ BLUD yakni salah satu didalamnya adalah efisiensi.

Secara umum sesuai dengan tujuannya, penerapan sistem jaminan kesehatan nasional disuatu negara akan membawa dampak positif yakni meningkatnya akses masyarakat ke pelayanan kesehatan termasuk didalamnya rumah sakit, tetapi sistem ini juga dapat memberi dampak negatif khususnya bagi rumah sakit dikarenakan adanya perubahan mendasar yang terjadi dalam sistem pelayanan kesehatan khususnya perubahan dalam sistem pembayaran ke rumah sakit yang jika tidak diantisipasi dengan baik oleh pihak manajemen maka akan mempengaruhi efisiensi dan efektifitas pelayanan di rumah sakit.

Secara umum terdapat dua alasan penting mengukur efisiensi sebuah organisasi termasuk rumah sakit. Pertama, bahwa efisiensi merupakan indikator keberhasilan dan tolok ukur kinerja suatu organisasi pada saat dilakukan suatu evaluasi. Kedua, dengan mengetahui tingkat efisiensi organisasi maka dapat diidentifikasi faktor yang mempengaruhi tingkat efisiensi dan produktifitas yang dicapai, baik dari lingkungan internal maupun lingkungan eksternal organisasi.

Hasil penelitian tentang penilaian efisiensi RS pada tahun 2017 di Indonesia memperlihat- 
kan bahwa masih terdapat $65.9 \%$ rumah sakit di Indonesia yang belum efisien secara teknis jika dibandingkan dengan rumah sakit lainnya. Skor rata-rata tingkat efisiensi rumah sakit di Indonesia adalah $78.9 \%$. Hal penelitian tersebut juga menunjukkan masih perlu peningkatan kinerja rumah sakit khususnya jumlah output rumah sakit secara umum sebesar $21,1 \% .{ }^{2}$ Beberapa kendala yang dihadapi oleh rumah sakit yang berdampak terhadap layanan operasional dan tingkat efisiensi di Era JKN saat ini antara lain seperti sering terhambatnya pembayaran klaim, pendapatan menurun, tarif dianggap belum rasional serta sistem rujukan yang belum berjalan dengan baik menjadi hambatan yang paling dirasakan oleh sebuah rumah sakit. ${ }^{3,4}$

Tujuan penelitian ini adalah mengetahui dampak penerapan kebijakan JKN terhadap tingkat efisiensi rumah sakit BLUD khususnya di Provinsi Sulawesi Selatan. Data penelitian diperoleh dari 25 rumah sakit badan layanan umum daerah di Provinsi Sulawesi Selatan. Data diperoleh secara primer dari RS tempat penelitian. Data yang dianalisis adalah data dari tahun 2014 yang merupakan awal penerapan kebijakan Jaminan Kesehatan Nasional di Indonesia hingga tahun 2017.

\section{BAHAN DAN METODE}

Penelitian ini adalah penelitian kuantitatif menggunakan rancangan observasional dengan jenis studi potong lintang (cross sectional). Sampel adalah seluruh rumah sakit umum yang telah berstatus Badan Layanan Umum Daerah di Provinsi Sulawesi Selatan. Jumlah sampel penelitian sebanyak 25 rumah sakit. Data diperoleh dari laporan rutin tahunan rumah sakit. Data yang dianalisis adalah data tahun 2014 hingga 2017 sehingga jumlah DMUs yang dianalisis atau diobservasi sebanyak 100 DMUs.

Penelitian ini menggunakan pendekatan non-parametrik dengan metode Data Envelopment Analysis untuk menilai tingkat efisiensi rumah sakit. Penelitan yang dilakukan oleh Hussey, dkk. menemukan bahwa mayoritas metode yang digunakan mengukur efisiensi dibidang kesehatan adalah metode frontier analysis termasuk didalamnya metode DEA. ${ }^{5}$ Kelebihan DEA adalah mampu mengakomodasi banyak input maupun output dalam banyak dimensi. Pengukuran efisiensi yang didapatkan pun lebih akurat dikarenakan pada rumah sakit, input dan outputnya sangat beragam dan saling terkait satu dengan yang lainnya. Adapun model matematika dari perhitungan DEA dapat digambarkan sebagai berikut:

$$
\begin{aligned}
& \max E_{m}=\frac{\sum_{J=0}^{j} v_{j m} y_{j m}}{\sum_{i=0}^{i} u_{i m} x_{i m}} \\
& \text { Subject to } \\
& 0 \leq \frac{\sum_{J=0}^{j} v_{j m} y_{j m}}{\sum_{i=0}^{i} u_{i m} x_{i m}} \leq 1 ; n=1,2, K, N \\
& v_{j m} u_{j m} \geq 0 ; i=1,2, K, I ; j=1,2, K, J
\end{aligned}
$$

\section{Keterangan :}

Em adalah efisiensi dari DMU ke $m$ yjm adalah output ke j dari DMU ke m vjm adalah bobot dari output di atas xim adalah input ke i dari DMU ke $m$ uim adalah bobot dari input di atas yjn dan xin adalah output ke j dan input ke i, berturut-turut, dari DMU ke $n, n=1,2, \mathrm{~N}$

Dalam menentukan indikator input dan output, penelitian ini memperhatikan dua hal yakni hasil studi terdahulu mengenai penggunaan indikator input dan output di rumah sakit dengan pendekatan DEA serta ketersediaan data indikator tersebut di rumah sakit khususnya ketersediaan data secara lengkap dari tahun 2014-2017.

Indikator input dalam penelitian ini terdiri dari Luas Bangunan $\mathrm{RS}^{6}$, Total Aset $\mathrm{RS}^{7,8}$, Biaya Operasional ${ }^{9}$ Biaya Farmasi ${ }^{9}$ Indikator output terdiri dari Jumlah Pasien ${ }^{8}$, Jumlah Pemeriksaan Laboratorium ${ }^{10,11}$ Jumlah Tindakan Operasi ${ }^{7}$, Pendapatan Operasional $\mathrm{RS}^{7}$, Average Length of Stay (Av-LOS) ${ }^{12}$, Turn Over Interval (TOI) ${ }^{13}$. Terdapat beberapa jenis model DEA yang mungkin digunakan tergantung dari kondisi permasalahan yang dihadapi. Jenis model DEA dapat diidentifikasi berdasarkan skala ekonomis dan orientasi dari model. Terdapat empat model DEA yang dapat digunakan dalam penelitian, yaitu CRS Input, CRS Output, VRS Input, dan VRS Output. CRS dan VRS menunjukkan asumsi yang digunakan, sedangkan input dan output menunjukkan orientasi dari penelitian. ${ }^{14}$ 
Penelitian ini menggunakan model DEA dengan asumsi VRS dan orientasi output dikarenakan subjek penelitian adalah rumah sakit pemerintah yang diasumsikan lebih mudah dalam mengontrol output mereka dibandingkan dengan input karena sifatnya yang sudah given dari pemerintah serta adanya aturan-aturan terkait standar input dari pemerintah.

\section{HASIL}

Hasil penelitian menunjukkan bahwa rata-rata jumlah input dan output rumah sakit di Provinsi Sulawesi Selatan dari tahun 2014 hingga 2017 mengalami peningkatan. Tabel 1 menunjukkan terjadi peningkatan jumlah total aset RS BLUD di Provinsi Sulawesi Selatan dari tahun ketahun. Pada tahun 2014 rata-rata total aset RS sebesar Rp.70.096.613.073, tahun 2015 sebesar Rp.78.172.425.081, tahun 2016 sebesar Rp.96.882.950.783 dan tahun 2017 sebesar Rp.124.299.310.659. Selanjutnya biaya operasional RS BLUD di Provinsi Sulawesi Selatan secara rata-rata mengalami peningkatan yakni pada tahun 2014 sebesar Rp.50.512.989.225, tahun 2015 sebesar Rp.57.988.247.173, tahun 2016 sebesar Rp.67.541.463.699 dan tahun 2017 sebesar Rp.74.572.852.036. Hal yang sama juga untuk rata-rata biaya farmasi rumah sakit, terjadi peningkatan cukup signifikan dari tahun ke tahun yakni pada tahun 2014 sebesar Rp.7.166.062.579, tahun 2015 Rp.9.674.360.869, tahun 2016 Rp.10.983.580.720 dan tahun 2017 sebesar Rp.12.477.068.194. Peningkatan jumlah biaya rumah sakit baik biaya operasional maupun biaya farmasi tidak terlepas dari semakin membesarnya atau bertambahnya skala produksi rumah sakit, dapat dilihat dari bertambahnya jumlah pasien yang harus dilayani oleh rumah sakit dari tahun ke tahun.

Tahun 2014 rata-rata RS melayani pasien sebanyak 59.357 pasien dengan jumlah pemeriksaan laboratorium sebanyak 33.747 pemeriksaan, jumlah tindakan operasi sebanyak 1.969 prosedur, jumlah pendapatan operasional sebanyak Rp.30.749.122.846 dengan Av-LOS 3,8 hari dan dan TOI 2,6 hari. Pada tahun 2017 seluruh output RS ini meningkat signifikan menjadi 78.902 pasien dengan jumlah pemeriksaan laboratorium sebanyak 43.573 pemeriksaan, jumlah tindakan operasi sebanyak 2.627 prosedur, jumlah pendapatan

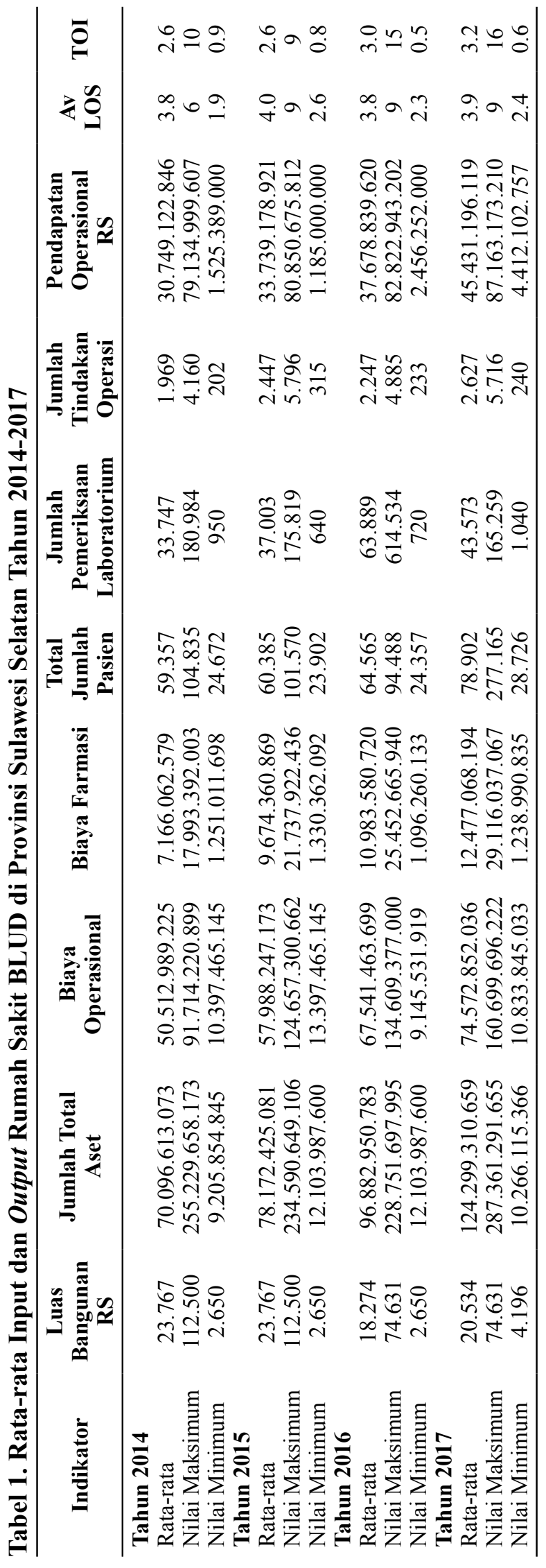


operasional sebanyak Rp.45.431.196.119 dengan Av-LOS 3.9 hari dan TOI 3,2 hari. Peningkatan jumlah output RS ini merupakan dampak langsung dari kebijakan implementasi program Jaminan Kesehatan Nasional yang telah dimulai sejak tahun 2014. Dengan adanya program ini maka akses masyarakat di Provinsi Sulawesi Selatan khususnya dari segi pembiayaan semakin meningkat.

Dengan menggunakan model 'output-oriented' dan model Variable Returns to Scale (VRS), skor super efisiensi teknis untuk rumah sakit dihitung dengan metode DEA. Skor super efisiensi teknis rumah sakit disajikan pada Tabel 2. Sebanyak 25 rumah sakit sampel penelitian yang diberi label dengan menggunakan nomor Kode RS secara nasional yang dikeluarkan oleh Kementerian Kesehatan Republik Indonesia.

DEA adalah teknik berbasis program linier untuk mengukur efisiensi unit organisasi yang dinamakan Decision Making Units (DMUs). Data Envelopment Analysis membandingkan tingkat efisiensi suatu Decision Making Units (DMUs) dengan menggunakan input dan output yang beragam dengan DMU yang sejenis. Sebuah DMUs dengan nilai kurang dari 1 adalah unit yang tidak efisien dan lebih dari 1 adalah efisien.

Hasil penelitian menunjukkan, pada tahun 2014 terdapat 11 rumah sakit (44\%) yang tidak efisien (nilai efisiensi $<1$ ) dan 14 rumah sakit (56\%) yang masuk dalam kategori efisien (nilai efisiensi $\geq 1$ ) dengan rata-rata tingkat efisiensi RS BLUD di Provinsi Sulawesi Selatan pada tahun 2014 sebesar 0,977. Pada tahun 2015 jumlah rumah sakit yang tidak efisien meningkat menjadi 13 rumah sakit (52\%) dan 12 rumah sakit (48\%) yang masuk dalam kategori efisien. Namun secara rata-rata tingkat efisiensi RS BLUD di Provinsi Sulawesi Selatan pada tahun 2015 meningkat dibanding pada tahun 2014 dengan skor sebesar 0,992. Pada tahun 2016 dan 2017 jumlah rumah sakit yang tidak efisien kembali meningkat menjadi 17 rumah sakit $(68 \%)$ dan hanya 8 rumah sakit (32\%) yang masuk dalam kategori efisien. Ratarata tingkat efisiensi RS BLUD di Provinsi Su-

Tabel 2. Skor Efisiensi Teknis Rumah Sakit di Provinsi Sulawesi Selatan Tahun 2014-2017

\begin{tabular}{cccccc}
\hline Kode RS & $\mathbf{2 0 1 4}$ & $\mathbf{2 0 1 5}$ & $\mathbf{2 0 1 6}$ & $\mathbf{2 0 1 7}$ & Mean \\
\hline RS 7303010 & 1,363 & 0,882 & 0,838 & 1,550 & 1,158 \\
RS 7311010 & 0,630 & 0,518 & 0,357 & 0,496 & 0,500 \\
RS 7308041 & 1,043 & 1,063 & 1,040 & 0,769 & 0,979 \\
RS 7302016 & 1,055 & 1,019 & 0,933 & 0,871 & 0,970 \\
RS 7317075 & 0,814 & 2,212 & 1,191 & 1,484 & 1,425 \\
RS 7325016 & 0,774 & 0,706 & 0,701 & 0,737 & 0,730 \\
RS 7317053 & 0,863 & 0,790 & 0,829 & 0,807 & 0,822 \\
RS 7371395 & 0,627 & 0,619 & 0,685 & 0,648 & 0,645 \\
RS 7371362 & 0,351 & 0,551 & 0,403 & 0,394 & 0,425 \\
RS 7371026 & 0,488 & 0,446 & 0,541 & 0,486 & 0,490 \\
RS 7371014 & 1,440 & 1,097 & 1,137 & 0,949 & 1,156 \\
RS 7309016 & 0,681 & 0,802 & 0,786 & 0,617 & 0,722 \\
RS 7373016 & 1,046 & 1,320 & 1,490 & 0,465 & 1,080 \\
RS 7310016 & 1,030 & 1,344 & 0,999 & 0,866 & 1,060 \\
RS 7372075 & 0,737 & 0,408 & 0,426 & 0,427 & 0,500 \\
RS 7315014 & 0,588 & 0,560 & 0,611 & 0,896 & 0,664 \\
RS 7301015 & 1,182 & 1,829 & 1,020 & 1,363 & 1,349 \\
RS 7314024 & 1,410 & 1,056 & 0,702 & 2,563 & 1,433 \\
RS 7314013 & 1,331 & 1,165 & 0,766 & 0,693 & 0,989 \\
RS 7307014 & 1,184 & 1,322 & 0,796 & 1,189 & 1,123 \\
RS 7312011 & 1,113 & 0,891 & 9,395 & 1,227 & 3,157 \\
RS 7305012 & 0,677 & 0,631 & 1,050 & 1,192 & 0,888 \\
RS 7318054 & 1,132 & 1,114 & 0,994 & 0,890 & 1,033 \\
RS 7313012 & 1,074 & 0,609 & 0,827 & 0,730 & 0,810 \\
RS 7313023 & 1,798 & 1,846 & 1,268 & 1,001 & 1,478 \\
Average & $\mathbf{0 , 9 7 7}$ & $\mathbf{0 , 9 9 2}$ & $\mathbf{1 , 1 9 1}$ & $\mathbf{0 , 9 3 2}$ & $\mathbf{1 , 0 2 3}$ \\
\hline
\end{tabular}




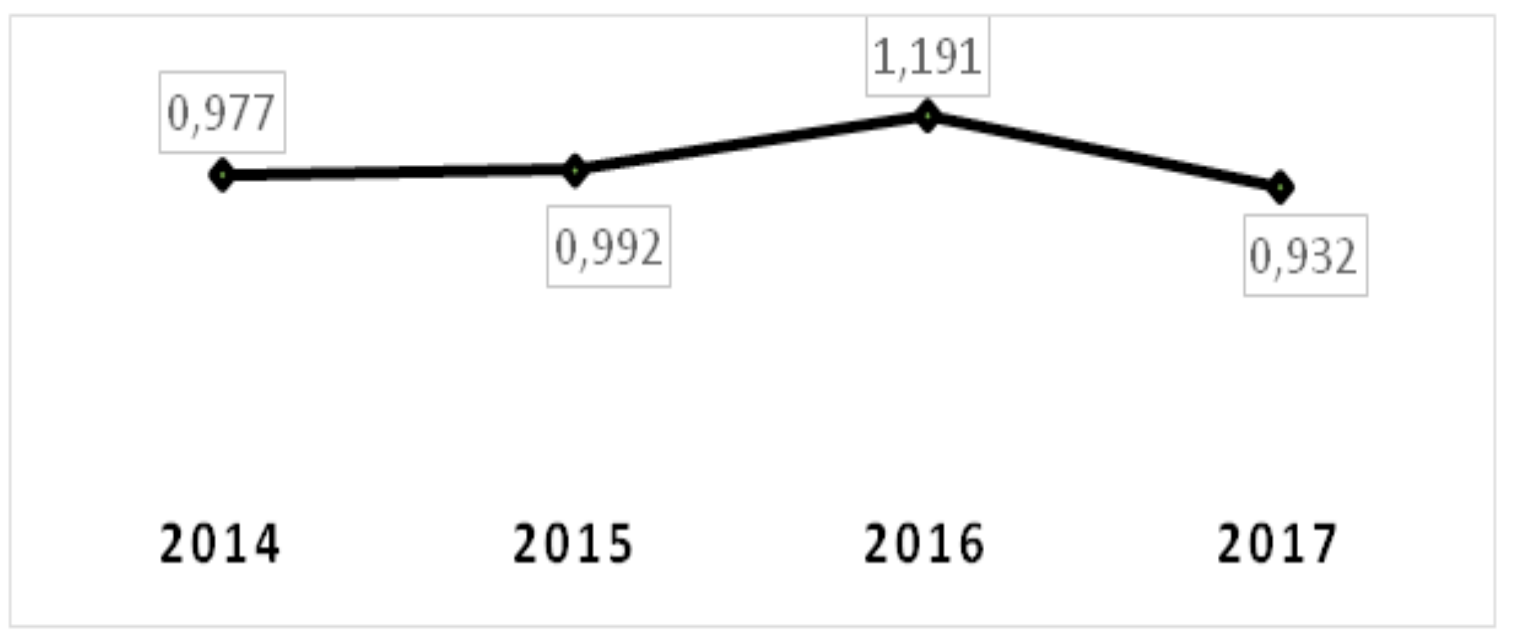

\section{Gambar 1. Dampak Implementasi Program JKN terhadap Tingkat Efisiensi Rumah Sakit di Provinsi Sulawesi Selatan, tahun 2014-2017}

lawesi Selatan pada tahun 2016 meningkat jika dibandingkan dengan tahun 2015 yakni menjadi sebesar 1,191, tetapi kembali memperlihatkan penurunan pada tahun 2017 menjadi 0,932 atau menjadi tidak efisien.

\section{PEMBAHASAN}

Dalam kurun waktu 4 (empat) tahun pelaksanaan program JKN di Indonesia khususnya di Provinsi Sulawesi Selatan, dapat dilihat bahwa program ini telah memberikan dampak terhadap perubahan tingkat efisiensi teknis rumah sakit (Gambar 1). Secara teoritis, implementasi kebijakan penerapan asuransi kesehatan secara universal disatu sisi akan memiliki dampak positif yakni meningkatnya akses dan jumlah kunjungan masyarakat ke fasilitas pelayanan kesehatan, tetapi disisi lain kebijakan ini juga telah menguras sumber daya yang besar dan memerlukan pengawasan secara intensif. Hasil penelitian memperlihatkan pada tahun 2014 rata-rata rumah sakit di Provinsi Sulawesi Selatan memiliki skor $<1$ atau tidak efisien. Penerapan program JKN secara nasional dari beberapa hasil penelitian lain memperlihatkan adanya dampak negatif terhadap kinerja keuangan, produktivitas dan efisiensi rumah sakit. Hal ini disebebakan beberapa faktor diantaranya hasil penelitian Malonda, menunjukan pada awal implementasi terjadi masalah terhambatnya pembayaran klaim BPJS Kesehatan. ${ }^{4}$ Chriswardani pada tahun 2015 juga menemukan bahwa pada tahun perta- ma pendapatan rumah sakit akan cenderung turun karena sebagian tarif INA-CBG lebih rendah dari pada tarif RS. ${ }^{3}$

Hal yang sama juga dialami oleh rumah sakit di Provinsi Sulawesi Selatan, berdasarkan hasil wawancara yang dilakukan kepada para pihak manajemen rumah sakit, salah satu permasalahan yang dialami rumah sakit dan dapat mempengaruhi tingkat efisiensi serta mutu layanan mereka adalah permasalahan sering terlambatnya pembayaran klaim pengobatan yang dibayarkan oleh pihak BPJS Kesehatan. Hal ini sangat mengganggu operasional rumah sakit karena arus kas yang tersendat, menyebabkan pelayanan di rumah sakit terganggu seperti keterlambatan pembayaran obat kepada pihak ketiga yang menyebabkan kekosongan obat serta keterlambatan pembayaran jasa pelayanan kepada staf rumah sakit yang jika kondisi tersebut terus berlangsung dapat berpengaruh terhadap kinerja, kepuasan dan motivasi staf rumah sakit.

Selanjutnya Gambar 1 memperlihatkan bahwa seiring berjalannya waktu, tingkat efisiensi rumah sakit di Provinsi Sulawesi Selatan mulai mengalami peningkatan. Pada tahun 2015 rata-rata tingkat efisiensi teknis rumah sakit meningkat dibanding tahun 2014 yakni menjadi 0,992, tetapi secara umum skor rata-rata tersebut masih dibawah 1 atau tidak efisien. Pada tahun 2016 rata-rata skor efisiensi rumah sakit meningkat menjadi 1,191 atau telah mencapai tingkat efisien. Namun, pada 
tahun 2017 tingkat efisiensi rumah sakit kembali mengalami penurunan menjadi 0,932 (tidak efisien). Berdasarkan hasil wawancara ditemukan beberapa persoalan eskternal yang memengaruhi efisiensi rumah sakit khususnya pada saat ini dalam penerapan program JKN adalah seringnya terjadi keterlambatan pembayaran klaim BPJS Kesehatan dan beberapa tarif INA CBGs yang masih belum rasional sehingga biaya real yang dikeluarkan oleh rumah sakit lebih besar dibanding tarif yang diterima. Hal ini secara sistemik telah membawa dampak negatif terhadap tingkat efisiensi rumah sakit.

Sebuah studi literatur yang dilakukan untuk mengetahui dampak sistem pembayaran berdasarkan paket pelayanan DRG terhadap efisiensi rumah sakit yang dipublikasikan di Inggris dari tahun 1984 hingga 2009 memperlihatkan hasil bahwa terdapat pengaruh sistem pembayaran DRG dengan efisiensi teknis rumah sakit di Portugal, Swedia, Norwegia. ${ }^{15}$ Demikian juga pada rumah sakit regional di China, hasil penelitian memperlihatkan bahwa reformasi asuransi kesehatan memiliki dampak terhadap efisiensi rumah sakit regional di China. Dengan menggunakan pendekatan DEA hasil penelitian tersebut menemukan dari tahun 2002-2008 tingkat efisiensi rumah sakit meningkat dari 0,6777 menjadi $0,8098 .{ }^{8}$

Beberapa literatur hasil penelitian sebelumnya memperlihatkan bahwa pada awal-awal penerapan kebijakan jaminan kesehatan disuatu negara pengaruhnya terhadap tingkat efisiensi baru dapat teramati pada tahun keenam pengamatan. Penelitian yang dilakukan di China memperlihatkan hasil, pada periode 2002 hingga 2008 dampak perubahan efisiensi belum terlihat dan masih sangat fluktuatif, sedangkan mulai pada tahun 2009 hingga tahun 2013 pengamatan mulai dapat terlihat adanya peningkatan atau hubungan yang positif terhadap tingkat efisiensi rumah sakit. ${ }^{7}$

Diharapkan beberapa perbaikan perlu dilakukan dari segi kebijakan agar kedepannya tingkat efisiensi rumah sakit tidak terus mengalami penurun terlebih dalam lingkungan implementasi program JKN seperti saat ini yang menuntut rumah sakit untuk dapat berproduksi secara efisien dan efektif dengan tetap memperhatikan mutu pelayanan. Terdapat dua faktor penyebab utama yang menganggu tingkat efisiensi rumah sakit saat ini. Pertama adalah besaran tarif INA-CBGs yang dianggap masih belum rasional oleh rumah sakit, masih terjadi selisih besaran biaya real yang dikeluarkan oleh rumah sakit pada beberapa kasus tindakan dengan tarif INA-CBGs. Kedua adalah masih seringnya terjadi keterlambatan pembayaran klaim BPJS Kesehatan ke rumah sakit. Kedua kondisi tersebut telah membawa dampak sistemik dan berpengaruh terhadap kinerja efisiensi rumah sakit. Pemerintah perlu segera mengeluarkan kebijakan perbaikan tarif INA-CBGs yang diamanatkan untuk dilakukan setiap dua tahun sekali dimana tarif yang ada saat ini terakhir di-update pada tahun 2016 dan hingga kini belum kembali dilakukan perbaikan. Selanjutnya permasalahan seringnya terjadi keterlambatan pembayaran klaim BPJS Kesehatan ke rumah sakit harus segera diselesaikan oleh pemerintah saat ini agar tidak mengganggu cash flow rumah sakit yang akan berdampak pada pelayanan operasional, mutu dan efisiensi rumah sakit.

\section{KESIMPULAN DAN SARAN}

Implementasi program jaminan kesehatan nasional saat ini di Indonesia telah membawa dampak terhadap tingkat efisiensi rumah sakit. Faktor utama yang sangat mempengaruhi tingkat efisiensi rumah sakit adalah seringnya terjadi keterlambatan pembayaran klaim pengobatan oleh BPJS Kesehatan serta besaran tarif INA-CBGs yang dianggap belum rasional. Berdasarkan hal tersebut maka diharapkan pemerintah untuk lebih memperhatikan kedua faktor tersebut agar kedepannya tingkat efisiensi rumah sakit dapat meningkat dan pada akhirnya kualitas layanan kepada masyarakat akan semakin membaik.

\section{DAFTAR PUSTAKA}

1. Kemendagri. Badan Layanan Umum Daerah [Internet]. Dirjen Bina Keuangan Daerah, Kementerian Dalam Negeri Republik Indonesia. 2017. Available from: http://keuda.kemendagri.go.id/datin/index/3/2016

2. Harmadi SHB, Irwandy. Technical Efficiency of Public Service Hospitals in Indonesia: A Data Envelopment Analysis (DEA). Asian Soc Sci. 2018;14(6):81-90.

3. Chriswardani S, Sutopo P, Putri Asmita W, Pawit $\mathrm{S}$, Puri Nur M. Implementasi JKN dan 
Permasalahan di Rumah Sakit di Kota Semarang Tahun 2014. In: Kongres INA-HEA 2016. Semarang; 2015.

4. Malonda TD, Rattu AJM, Soleman T. Analisis Pengajuan Klaim Badan Penyelenggara Jaminan Sosial (BPJS) Kesehatan di RSUD Dr. Sam Ratulangi Tondano. Univesitas Sam Ratulangi; 2015.

5. Hussey PS, Vries H De, Romley J, Wang MC, Chen SS, Shekelle PG, et al. Health Care Efficiency A Systematic Review of Health Care Efficiency Measures. Heal Res Educ Trust. 2008;784-805.

6. Araújo C, Barros CP, Wanke P. Efficiency Determinants and Capacity Issues in Brazilian for Profit Hospitals. Health Care Manag Sci. 2014 Jun;17(2):126-38.

7. Chu K, Zhang N, Chen Z. The Efficiency and Its Determinants for China's Medical Care System: Some Policy Implications for Northeast Asia. Sustainability. 2015;7:14092-111.

8. Hsin-hui H, Qinghui Q, Chih-hai Y. Analysis of Hospital Technical Efficiency in China : Effect of Health Insurance Reform. China Econ Rev. 2012;23(4):865-77.

9. Varabyova Y, Schreyögg J. International Comparisons of the Technical Efficiency of the Hospital Sector: Panel Data Analysis of OECD Countries Using Parametric and
Non-Parametric Approaches. Health Policy (New York). 2013 Sep;112(1-2):70-9.

10. Karagiannis R. A System of Equations Two Stage DEA Approach for Explaining Capacity Utilization and Technical Efficiency. Ann Oper Res. 2013 Apr;227(1):25-43.

11. Nicola A De, Gitto S, Mancuso P, Tor R. A Two Stage DEA Model to Evaluate the Efficiency of the Italian Health System. Munich Pers RePEc Arch. 2011;(39126).

12. Sulku SN. The Health Sector Reforms and the Efficiency of Public Hospitals in Turkey: Provincial Markets. Eur J Public Health. 2012;22(5):634-8.

13. Direktorat Jenderal Bina Upaya Kesehatan. Juknis Sistem Informasi Rumah Sakit. Jakarta, Indonesia; 2011.

14. Shahhoseini R, Tofighi S, Jaafaripooyan E, Safiaryan R. Hospitals Efficiency Measurement in Developing Countries: Application of Data Envelopment Analysis for Iranian. Heal Serv Manag Res. 2011;24(2):75-80.

15. Tabrizi HM. Impact of DRG Reimbursement System on Hospital Efficiency: Systematic Review. BMC Health Serv Res [Internet]. 2012;12(Suppl 1):O2.

16. TNP2K. The Road to National Health Insurance (JKN). 2015. 